\title{
ANÁLISIS COMPARATIVO DE PRECIOS Y COSTOS DE PRODUCCIÓN DE HORTALIZAS CULTIVADAS DE MANERA ORGÁNICA Y CONVENCIONAL
}

\author{
Silvia Elena Arce Quesada
}

Palabras clave: Agricultura orgánica; agricultura convencional; costos de producción; precio de venta. Keywords: Organic agriculture; conventional agriculture; production costs; selling price.

Recibido: 20/11/2019

RESUMEN

Introducción. La presente investigación es el primer esfuerzo identificado en Costa Rica, que concreta una comparación de costos de producción entre hortalizas orgánicas y convencionales. El proyecto permitió visibilizar los precios de venta, costos unitarios y márgenes de ganancia de los productos seleccionados y los comparó entre ambos esquemas de producción. Objetivo. Esclarecer las causas asignables a la diferencia en precios de venta y costos de producción entre 6 hortalizas orgánicas y su homólogo convencional. Materiales y métodos. Se formuló un cuestionario para consultar a 2 grupos de productores, uno conformado por 10 productores de hortalizas orgánicas y otro por 10 productores dedicados a la producción convencional. Se formularon 19 preguntas cerradas sobre costos de inversión, costos de producción, ingresos, relación costo-beneficio. Las hortalizas seleccionadas fueron culantro (Coriandrum sativum), lechuga (Lactuca sativa), papa (Solanum tuberosum), zanahoria (Daucus carota), apio (Apium graveolens) y brócoli (Brassica oleracea). Los datos
Aceptado: 16/04/2020

1 Autora para correspondencia. Correo electrónico: silvia.arce@ucr.ac.cr Universidad de Costa Rica, Centro de Investigaciones en Economía Agrícola y Agronegocios, Costa Rica. (D) 0000-0003-0807-4103. 
registrados fueron agrupados por costos de producción y precio de venta en ferias del agricultor. Resultados. El precio de venta de los productos orgánicos por unidad comercializada fue superior al de prácticas convencionales en todos los casos. Se logró determinar que la diferencia porcentual en precios para zanahoria fue de $28,57 \%$, apio $40 \%$, 25\% para culantro, $53,33 \%$ para papa, 33,33\% para lechuga y $66,67 \%$ para broccoli. Además, se evidenció que los productos convencionales presentaron mayor costo total de producción con respecto a los productos orgánicos, esto es un $41,70 \%$ superior para zanahoria, $65,18 \%$ para apio, $29,03 \%$ para culantro, $34,78 \%$ para papa, $16,65 \%$ para lechuga y $44,91 \%$ para brócoli. Conclusiones. Las actividades con prácticas convencionales expusieron costos superiores, debido a la demanda y compra de insumos externos y a la utilización de métodos de tránsito y rodaje de maquinaria, mientras que la producción orgánica propone baja dependencia de compra de insumos externos, ya que los requeridos son generados fundamentalmente en la propia finca y los productores llevan a cabo prácticas que promueven la salud del agroecosistema, la biodiversidad y los ciclos biológicos.

\section{INTRODUCCIÓN}

Por medio de la investigación se logró un análisis comparativo de costos de producción entre productos orgánicos y convencionales. Las hortalizas investigadas fueron culantro (Coriandrumsativum), lechuga (Lactuca sativa), papa (Solanumtuberosum), zanahoria (Daucus carota), apio (Apiumgraveolens) y brócoli (Brassicaoleracea). Según datos del Programa Integral de Mercadeo Agropecuario (PIMA), las 6 hortalizas seleccionados se encuentran en las listas de productos utilizados por su capacidad nutricional en comedores infantiles. Un estudio realizado por dicha institución hace referencia a que el
(Brassica oleracea). Recorded data was grouped by production costs and sale prices at farmers markets. Results. Sale prices of organic products per unit sold was higher than that of conventional practices in all cases. It was possible to determine that the percentage difference in prices for carrots was $28.57 \%, 40 \%$ for celery $40 \%, 25 \%$ for cilantro, $53.33 \%$ for potatoes, $33.33 \%$ for lettuce and $66.67 \%$ for broccoli. In addition, conventional products presented higher total cost of production with respect to organic products, this was $41.70 \%$ higher for carrots, $65.18 \%$ for celery, $29.03 \%$ for cilantro, $34.78 \%$ for potatoes, $16.65 \%$ for lettuce and $44.91 \%$ for broccoli. Conclusions. The activities with conventional practices exposed higher costs, due to the demand and purchase of external inputs and the use of machinery, while organic production proposes low dependence on the purchase of external inputs, since those required are mainly generated on the own farm as producers adopt practices that promote the health of the agroecosystem, biodiversity and biological cycles.

comportamiento hacia el consumo de hortalizas al igual que el de frutas ha variado en los años registrados. En el 2002, el consumo per cápita era de 98,38 kg, para el 2003- 2004 presentó una disminución de 18,27 kilos, para registrar el menor consumo de 80,11 kg. Después de este año el comportamiento mostró un crecimiento de $100,48 \mathrm{~kg}$ para el 2012 y para el 2015 los hogares costarricenses habían consumido 112,57 $\mathrm{kg}$, donde los adultos de 22-59 años fueron los principales consumidores en segundo lugar los niños de 0-12 años PIMA (2016).

Esta investigación es el primer acercamiento a una comparación entre costos de producción entre productos orgánicos y convencionales 
en Costa Rica. El proyecto permitió visibilizar los precios de venta, costos unitarios y márgenes de ganancia de los productos seleccionados en ambos esquemas de producción. Se desarrolló como un diagnostico, ya que es un primer acercamiento a un análisis comparativo de costos para un grupo de hortalizas previamente seleccionadas. El diagnostico surge de un muestreo no probabilístico, ya que la muestra seleccionada obedece a una población accesible, que son individuos fácilmente disponibles pertenecientes a la población de interés identificados por el Ministerio de Agricultura y Ganadería del país.

El estudio contempla como actividad orgánica a toda aquella producción que se sustenta en sistemas naturales para mantener y recuperar la fertilidad de los suelos, la diversidad biológica y el manejo adecuado del recurso hídrico, y que propicie los ciclos biológicos en el uso del suelo. Esta actividad desecha el uso de agroquímicos sintéticos, cuyo efecto tóxico afecte la salud humana y el ambiente, así como el uso de organismos transgénicos, (Ley Orgánica del Ambiente 7554 de 1995). La agricultura convencional es el sistema de producción agropecuaria en la que se utilizan sustancias químicas sintéticas de manera parcial o total, es un sistema extremadamente artificial basado en el alto consumo de insumos externos sin considerar los ciclos naturales (Manual de lumbricultura sf).

Este estudio fue estructurado y pormenorizado de forma tal que facilitara la comprensión del origen de las diferencias de costos entre los convencionales y orgánicos. Con este acercamiento también se buscó documentar la información que fue obtenida en fincas con el propósito de eliminar conjeturar sobre los posibles costos y los precios de venta de los productos analizados. El estudio también aporta información que podrá ser actualizada periódicamente de manera que se valide fundamentada en datos y no en percepciones. Se estableció un análisis de indicadores financieros para las 6 hortalizas estudiadas, los indicadores evaluados fueron el margen de ganancia y el costo- beneficio, que son herramientas de gran importancia para el flujo de información y toma de decisiones financieras de manera oportuna y asertiva. El costo beneficio compara de manera directa los beneficios y los costos de producción, es un indicador muy fácil de trabajar y analizar, además nos permite tomar decisiones cuando hay diversas alternativas. El margen de ganancias representa la rentabilidad de una empresa, el porcentaje de ganancias que le queda al productor después de haber cubierto todos los costos, es usualmente utilizado para determinar el éxito o el fracaso de un negocio comparándolo con otros de la misma industria.

Por medio de las encuestas realizadas en el campo se logró determinar que los productores han migrado de la agricultura tradicional a la orgánica. Los mismos indicaron que obedecía principalmente a la influencia y liderazgo de algunas personas productoras y también como resultado de la motivación obtenida a partir de capacitaciones en el Instituto Nacional de Aprendizaje (INA), el Ministerio de Agricultura y Ganadería (MAG) y por interés propio. Otras razones para el cambio fueron el rechazo al uso de sustancias sintéticas con historial de daños en la salud, aprovechamiento del uso alternativo de los materiales de la finca, así como la búsqueda de preservar semillas y prácticas empleadas en el pasado Gitli y Arce (2001).

El Servicio Fitosanitario del Estado (SFE) el cual posee un reglamento de agricultura orgánica MAG (2001) que entre otros aspectos, mantiene un registro en agricultura orgánica que con una base de datos, ha procurado autenticar la trazabilidad y control de la producción, pues ha de cumplir con una serie de lineamientos estipulados en reglamentos respaldados en las siguientes leyes que obedecen a la normativa específica que rige la agricultura orgánica en Costa Rica:

- $\quad$ Ley orgánica del ambiente 7554 de 1995

- Ley de protección fitosanitaria 7664 de 1997 y su reglamento

- Reglamento sobre la agricultura orgánica

- $\quad$ Decreto Ejecutivo 29782 del 2001, modifica al 25834 de 1997 y al 29067 de 2000. 
Las anteriores regulaciones y servicios operan para un área de producción de hortalizas orgánicas certificadas, de acuerdo con datos obtenidos por la Secretaría de Planificación del Sector Agropecuario, SEPSA (2016). Se estima que hay más de 9,800 ha dedicadas al cultivo de hortalizas, de las cuales 157,76 ha cultivadas con hortalizas orgánicas certificadas, lo cual equivale al 1,9\% de la producción SFE (2017).

De igual manera la FAO (2018) cita razonas por las que los productos orgánicos certificados suelen ser más costosos que sus equivalentes comunes:

- La oferta de alimentos orgánicos es limitada en relación con su demanda.

- Los costos de producción de los alimentos orgánicos suelen ser más elevados porque requieren más mano de obra por unidad de producción, sin embargo, el $80 \%$ de los productores analizados por Camacho et al. (2015) indicó utilizar mano de obra familiar (2,2 personas) y el resto utiliza mano de obra externa durante todo el año, en promedio una fuerza de trabajo de 3,5 personas, incluyendo al productor.

- La manipulación postcosecha de cantidades relativamente reducidas de alimentos orgánicos tiene un costo más alto por la separación obligatoria de los productos orgánicos respecto de los convencionales, especialmente durante la elaboración y el transporte.

- Los costos de comercialización y distribución de los productos orgánicos son más elevados por tratarse de volúmenes relativamente pequeños.

Es relevante destacar que tanto Organic Latin America (2018) como la FAO (2018) concuerdan con que los precios de los alimentos orgánicos no sólo comprenden el costo de la producción misma de los alimentos, sino también otra serie de factores y beneficios que no quedan contenidos en los precios de los alimentos convencionales, por ejemplo:
- La promoción y protección del medio ambiente (y evitar futuros gastos para mitigar la contaminación). Por ejemplo, los precios más altos de los cultivos orgánicos comerciales compensan las pocas ganancias o periodos de rotación necesarios para enriquecer la fertilidad del suelo.

- Mayor bienestar de los animales.

- $\quad$ Eliminación de riesgos a la salud de los agricultores por la manipulación inadecuada de plaguicidas y probablemente, eliminación de futuros gastos médicos.

- Desarrollo rural a través de la creación de más empleos agrícolas al asegurar un ingreso justo y suficiente para los productores.

Respecto al estudio, la única referencia comparable fue un análisis de costos para hortalizas ecológicas de Escobar (2003). Para el abordaje del tema se hizo referencia a los costos directos que son aquellos relacionados con la obtención del producto final, mientras que los indirectos afectan la actividad productiva, y están implícitos en el proceso, pero no en el producto final, García (2014).

El objetivo principal de esta investigación fue realizar un diagnóstico comparativo para determinar los costos de producción de 6 hortalizas orgánicas y su homólogo convencional para justificar las diferencias en el precio de venta.

\section{MATERIALES Y MÉTODOS}

Se realizó un diagnóstico comparativo para determinar los costos de producción de productos orgánicos y su homólogo convencional de manera que pudieran justificar el precio de venta de cada grupo de productos. Los datos aparecen actualizados hasta octubre del 2019. La información se obtuvo fundamentalmente de fuentes primarias; la misma conformó evidencias directas del tema, durante el período de vigencia del estudio.

Referente a el área de producción para cada hortaliza, se procedió a homologarlas 
para ambos sistemas de producción, con el fin de comparar los costos de producción por área cultivada. Sin embargo, se deben considerar las diferentes especificaciones técnicas de cada tipo de hortalizas por lo que sus áreas de producción difieren. Los productores fueron localizados y contactados a partir de listados que facilitó personal del Ministerio de Agricultura y Ganadería (MAG).

El instrumento utilizado se construyó con 19 preguntas enfocadas en los registros de producción, prácticas de producción, costos, ubicación, área de producción y paquete tecnológico. $\mathrm{El}$ instrumento fue valorado previamente por los productores entrevistados evaluando la comprensión y ajustes del instrumento.

Se realizó una encuesta a productores de la Zona de Cartago, Costa Rica para obtener los datos que permitieran formularla estructura de costos de 6 productos, tanto de manera convencional como orgánica, para poder definir el precio unitario según producción y comercialización del producto. Los 6 productos culantro (Coriandrumsativum), lechuga (Lactuca sativa), papa (Solanumtuberosum), zanahoria (Daucus carota), apio (Apiumgraveolens) y brócoli (Brassicaoleracea) se encuentran considerados dentro de la lista de principales productos de producción de la zona de Cartago. MAG (2007); según datos del VI Censo Agropecuario 2014, el 53\% INEC (2015), de las fincas de producción de hortalizas a nivel nacional se encuentran en esa provincia. El análisis se realizó como diagnóstico, sin embargo, es un primer acercamiento al tema a investigar.

\section{Selección de fincas}

Para la elección de las fincas orgánicas se contó con la ayuda del MAG de la Región Central Oriental, que facilitó para el estudio, una lista de productores certificados tanto de forma grupal como individual en la región, se eligieron productores que tuvieran alguna certificación orgánica, aspecto que favorece el levantamiento de datos, debido a que las empresas certificadoras les solicita llevar registros que se les constatan con visitas para su verificación. Estas inspecciones garantizan que los productores estén realizando las prácticas agrícolas correctas en el terreno y que no están usando químicos no permitidos. Los productores convencionales se eligieron según zona de producción donde tuvieran características similares en área de producción y mismo cultivo a los productores orgánicos para el análisis de datos. En los casos en que las áreas de producción de convencional fueron mayores al área de producción orgánica, se hizo un ajuste de proporcionalidad.

Se realizó la encuesta a 10 productores bajo el esquema de producción convencional y 10 a productores certificados orgánicos. En este último caso, se identificó que es común que los mismos productores realicen la venta en parte por el interés de informar a los consumidores sobre el valor de una producción agrícola diferenciada como orgánica. La encuesta se conformó de 19 preguntas cerradas, que incluían criterios que fueron previamente comentados y explicados a las personas entrevistadas, con el propósito de que pudieran suministrar información sobre costos de producción desglosados entre costos directos y costos indirectos, ingresos y relación costo- beneficio.

A partir de esa selección se recopilaron los datos sobre costos directos y asociados a la producción de culantro, lechuga, papa, zanahoria, apio y brócoli. Se seleccionaron 6 hortalizas para el análisis de las cuales según datos del MAG son de gran importancia económica en la región. Los productos analizados fueron: culantro (Coriandrumsativum), lechuga (Lactuca sativa), papa (Solanumtuberosum), zanahoria (Daucus carota), apio (Apiumgraveolens) y brócoli (Brassicaoleracea).

\section{Análisis de costos}

Se analizaron los costos de producción, concebidos como aquellos que representan todas las erogaciones hechas o por hacer, hasta que el producto esté listo para la finalidad a la que se destina. En este caso, los costos de producción 
de hortalizas engloban los precios que se han de pagar por los insumos y mano de obra; a la vez, los costos se clasificaron, en directos e indirectos. Para el presente diagnóstico no se consideraron los costos de inversión ya que las actividades estaban en operación y los activos requeridos ya formaban parte de las acciones. Fue preciso analizar los costos unitarios de los productos, ya que los precios en ferias agrícolas es común que se establezcan en unidades para su venta.

Para el análisis de los costos, no se estimó el impuesto de renta, ya que la ley $\mathrm{N}^{\circ}$. 8591, denominada Ley para el Desarrollo, Promoción y Fomento de la Actividad Agropecuaria Orgánica en el Artículo 28, declara que exonera del pago del impuesto sobre las ventas, los productos que son agropecuarios o agroindustriales certificados como orgánicos o inscritos en transición, ante la entidad correspondiente. En el caso de las personas productoras de hortalizas convencionales, ninguna reportó durante el período de la investigación, que incluyera el impuesto de renta por lo que tampoco se consideró el criterio para ese grupo.

\section{Ordenamiento de datos por tipo de costo}

En la Tabla 1 se exponen los criterios utilizados para determinar los costos directos de producción, considerados como aquellos en lo que ha incurrido el productor para la obtención de su cosecha. Dichos costos son específicos y fundamentalmente diferentes para cada tipo de producción de hortalizas.

Tabla 1. Costos directos de producción en producción orgánica y producción convencional.

\begin{tabular}{ll}
\hline Producción orgánica & Producción convencional \\
\hline Mano de obra & Labores contratadas \\
Control biológico & Mano de obra \\
Fertilizantes orgánicos & Fertilizantes sintéticos \\
Semillas & Semilla \\
\hline
\end{tabular}

Agronomía Costarricense 44(2): 81-108. ISSN:0377-9424 / 2020
Los datos registrados en la investigación exponen que en el manejo orgánico las actividades de producción son fundamentalmente realizadas sin contratación de maquinaria o animales, ya que los mismos productores señalaron que procuran así un manejo adecuado de la tierra para evitar la erosión. En la producción convencional es común que se utilice la contratación de maquinaria (labores contratadas) o equipo para la preparación del terreno.

La Tabla 2 muestra los costos indirectos de producción. Para ambos casos, se tomó en cuenta la depreciación de equipos y su mantenimiento. En la producción convencional se incluyó el uso de equipo de protección para los trabajadores, ya que las Buenas Prácticas Agrícolas (BPA) con la intención de garantizar la seguridad de los trabajadores. En el Código de Trabajo Costa Rica (1995) en el octavo capítulo artículo 284 establece que es obligación del patrón proporcionar el equipo y elemento de protección personal $\mathrm{y}$ de seguridad en el trabajo y asegurar su uso y funcionamiento.

Tabla 2. Costos indirectos de producción en producción orgánica y convencional.

\begin{tabular}{ll}
\hline *Producción orgánica & Producción convencional \\
\hline Análisis de suelo & Análisis de suelo \\
*Depreciación (no se incluye) & Equipo protección \\
Mantenimiento & Mantenimiento \\
Agua & Combustible \\
Combustible & Depreciación \\
Cajas & Agua \\
\hline
\end{tabular}

\section{RESULTADOS Y DISCUSIÓN}

El estudio se realizó en la provincia de Cartago durante el 2019; el análisis consistió en una comparación de costos de producción en sistema orgánico y convencional donde se estimó la utilidad generada por cada producto, así como el margen de ganancia, el costobeneficio, y el costo unitario de producción según medida de comercialización; en el caso 
de zanahoria, papa y brócoli se calcularon por kilo de producto; para lechuga y apio en unidades y para el culantro en rollos ya que son las unidades de venta.

Los costos analizados están en "colones", moneda costarricense que tiene una relación de 1 dólar $/ 590$ colones al 1 de noviembre del 2019. Se utilizó el programa Excel para tabular, organizar y generar la información de las estructuras de costos.

Antes de proceder al desglose para cada uno de los costos por producto, en la Tabla 3, se exponen los precios de venta por unidad de medida para los 6 productos tanto convencionales como orgánicos, consultados en ferias del agricultor.

Tabla 3. Precio en colones de los productos convencionales y orgánicos por unidad en feria del agricultor. Octubre, 2019.

\begin{tabular}{lcccc}
\hline Producto & Precio orgánico & Precio convencional & Diferencia de precio & Diferencia porcentual \\
\hline Zanahoria & $700 / \mathrm{kg}$ & $500 / \mathrm{kg}$ & 200 & $28,57 \%$ \\
Apio & $500 /$ mata & $300 /$ mata & 200 & $40,00 \%$ \\
Culantro & $200 /$ rollo & $150 /$ rollo & 50 & $25,00 \%$ \\
Papa & $1500 / \mathrm{kg}$ & $700 / \mathrm{kg}$ & 800 & $53,33 \%$ \\
Lechuga & $150 /$ unidad & $100 /$ unidad & 50 & $33,33 \%$ \\
Brócoli & $1500 / \mathrm{kg}$ & $500 / \mathrm{kg}$ & 1000 & $66,67 \%$ \\
\hline
\end{tabular}

$\mathbb{C}$ : símbolo colones. $\mathbb{C} 590=1 \$$ (noviembre 2019).

\section{Análisis de costos por producto}

Para los 6 cultivos estudiados se consideró costos de inversión, costos directos y costos indirectos, los cuales se establecieron de manera mensual, y costos administrativos. Cabe mencionar que este registro se simplificó para información procedente de fincas orgánicas ya que al ser certificadas se les pide por norma, que una persona contadora asuma el registro y control de cuentas.

Los costos de inversión varían según el tipo de cultivo. En los costos directos se consideraron mano de obra de manera mensual, el control biológico y fertilizantes orgánicos y la semilla, plántula o almacigo según cultivo.
En los costos indirectos se incluye el análisis de suelo exigido por la certificadora, depreciaciones mensuales, mantenimiento que en todos los casos incluye el cambio de aceite y el marchamo de vehículo, que no se contempla en este caso como inversión pues ya eran parte de los recursos y tampoco se incluye en la depreciación, debido a que estaban depreciados en su totalidad pero que aún trabajan en finca según señalaron los encuestados, aunque si se consideraron los costos de mantenimiento, el agua, combustible y las cajas necesarias para guardar el producto o traslados.

A continuación, se desglosan los costos para los productos seleccionados donde aparecen inicialmente. los de producción orgánica y luego la convencional. 


\section{Zanahoria orgánica}

En la Tabla 4, se exponen las estructuras de costos para la producción de 250 metros cuadrados de zanahoria, de las cuales se tuvo una producción mensual de $400 \mathrm{~kg}$.

En la Tabla 5 de inversión se incluyó un motocultivador que es comúnmente utilizado en la
Tabla 4. Especificaciones técnicas de la producción de zanahoria orgánica.

\begin{tabular}{lr}
\hline Área $\mathrm{m}^{2}$ & 250 \\
\hline Duración del ciclo & 4 meses \\
Rotaciones (anual) & 3 \\
Producción mensual & 400 \\
\hline
\end{tabular}

agricultura orgánica por su bajo impacto al suelo, la motoguadaña, bomba de motor y bomba estacionaria.

Tabla 5. Inversión en colones para la producción de zanahoria orgánica.

\begin{tabular}{|c|c|c|c|}
\hline Activos & Costo inversión & Depreciación anual & Depreciación mensual \\
\hline Motocultivador & 450000,00 & 45000 & 3750,00 \\
\hline Motoguadaña & 250000,00 & 25000 & 2083,33 \\
\hline Bomba-motor & 150000,00 & 30000 & 2500,00 \\
\hline Bomba estacionaria & 300000,00 & 60000 & 5000,00 \\
\hline Total & 1150000,00 & 160000,00 & 13333,33 \\
\hline
\end{tabular}

Dentro de los costos directos que aparecen en la Tabla 6 se consideró la mano de obra de una persona que trabaja 2 días a la semana medio tiempo cada día, que le genera un total de 40000 colones al mes, debido a que la cantidad de terreno es limitado y no es requerida a diario, una persona en el cultivo. Se estimó el precio de la semilla por la cantidad necesaria para $250 \mathrm{~m}^{2}$. Para los costos indirectos se estimó el análisis de uso de suelo que lo solicita la certificadora, la depreciación del equipo, el mantenimiento, incluyendo marchamo y aceite de los vehículos utilizados para transportar el producto, los vehículos no se incluyeron en la inversión, como se mencionó, los entrevistados expresaron que los autos utilizados ya cumplieron su ciclo depreciable, por lo que no se incluyen en la estructura, sin embargo, al utilizarlos en finca, requieren mantenimiento, con un monto estimado de combustible para el transporte de insumos y traslado de la producción. Fue incluido el rubro de cajas reutilizables para colocar el producto.
Tabla 6. Costos directos, indirectos, administrativos de zanahoria orgánica en colones.

\begin{tabular}{lr}
\hline Rubro & Costos directos \\
\hline Mano de obra & 40000,00 \\
Control biológico & 2588,00 \\
Fertilizantes orgánicos & 1198,75 \\
Semillas & 8500,00 \\
\hline Total & 52286,75 \\
\hline Rubro & 15000,00 \\
\hline Análisis de suelo & 13333,33 \\
Depreciación & 500,00 \\
Mantenimiento & 500,00 \\
Agua & 10000,00 \\
Combustible & 10000,00 \\
\hline Cajas reutilizables & 49333,33 \\
\hline Total & 10000 \\
\hline Rubro & 111620,08 \\
\hline Contador & Costos administrativos \\
\hline Total, costos de producción & \\
\hline Costo mensual & \\
\hline
\end{tabular}




\section{Apio orgánico}

En la Tabla 7 se encuentran las especificaciones técnicas para la producción de apio, se evaluó para $500 \mathrm{~m}^{2}$ con una producción mensual de 960 matas (planta de poca altura).

En la Tabla 8 de inversión se incluye el motocultivador, motoguadaña y las bombas de motor y estacionaria.
Tabla 7. Especificaciones técnicas de la producción de apio orgánico.

\begin{tabular}{lr}
\hline Área $\mathrm{m}^{2}$ & $500 \mathrm{~m}^{2}$ \\
\hline Duración del ciclo & 4 meses \\
Rotaciones (anual) & 3 \\
Producción mensual & 960
\end{tabular}

Tabla 8. Inversión para la producción de apio orgánico, en colones.

\begin{tabular}{|c|c|c|c|}
\hline Activos & Costo inversión & Depreciación anual & Depreciación mensual \\
\hline Motocultivador & 450000 & 45000 & 3750,00 \\
\hline Motoguadaña & 250000 & 25000 & 2083,33 \\
\hline Bomba-motor & 150000 & 30000 & 2500,00 \\
\hline Bomba estacionaria & 300000 & 60000 & 5000,00 \\
\hline Total & 1150000,00 & 160000,00 & 13333,33 \\
\hline
\end{tabular}

En la Tabla 9 en los costos directos se consideró un trabajador por 3 medios días a la semana, con un costo mensual de 60000 colones. Los costos indirectos incluyen el análisis de suelo solicitado por la certificadora, así como la depreciación del equipo, el mantenimiento que se explicó anteriormente y además se estimó el combustible necesario para el traslado de insumos y productos, así como cajas requeridas mensualmente.
Tabla 9. Costos directos, indirectos, administrativos de apio orgánico, en colones.

\begin{tabular}{lr}
\hline Rubro & Costos directos \\
\hline Mano de obra & 60000,00 \\
Control biológico & 5175,00 \\
Fertilizantes orgánicos & 2400,00 \\
Almacigo & 11500,00 \\
\hline Total & 79075,00 \\
\hline Rubro & Costos indirectos \\
\hline Análisis de suelo & 15000,00 \\
Depreciación & 13333,33 \\
Mantenimiento & 1000,00 \\
agua & 1000,00 \\
Combustible & 10000,00 \\
Cajas & 20000,00 \\
\hline Total & 60333,33 \\
\hline Rubro & 10000 \\
\hline Contador & 149408,33 \\
\hline Total costos de producción & Costos administrativos \\
\hline Costo mensual & \\
\hline
\end{tabular}




\section{Culantro orgánico}

En la Tabla 10 de especificaciones técnicas el estudio del culantro se realizó en $100 \mathrm{~m}^{2}$ con una producción de 1667 rollos mensuales.

En la Tabla 11 de costos en mano de obra se consideró una persona que labora 2 veces a la semana medio tiempo, por lo que son 40000 colones al mes, más los gastos necesarios de control biológico y fertilizantes orgánicos y la semilla necesaria para $\operatorname{los} 100 \mathrm{~m}^{2}$ de producción. Los costos indirectos son los parámetros señalados y justificados en análisis de suelo, mantenimiento y combustible más los gastos administrativos del contador.

\section{Papa orgánica}

La Tabla 12 muestra las especificaciones en la producción de papa, se realizó el análisis para $1000 \mathrm{~m}^{2}$ que generó una producción de 1472 kilos.
Tabla 10. Especificaciones técnicas de la producción de culantro orgánico en colones.

\begin{tabular}{lr}
\hline Area $^{2}$ & 100 \\
\hline Duración del ciclo & 1,5 meses \\
Rotaciones (anual) & 8 \\
Producción mensual & 1667
\end{tabular}

Tabla 11. Costos directos, indirectos, administrativos del culantro orgánico en colones.

\begin{tabular}{lr}
\hline Rubro & Costos directos \\
\hline Mano de obra & 40000,00 \\
Control biológico & 1035,00 \\
Fertilizantes orgánicos & 500 \\
Semilla & 1000,00 \\
\hline Total & 42535,00 \\
\hline Rubro & 15000,00 \\
\hline Análisis de suelo & 1000,00 \\
Mantenimiento & 5000,00 \\
\hline Combustible & 21000,00 \\
\hline Total & 10000 \\
\hline Rubro & Costos administrativos \\
\hline Contador & 73535,00 \\
\hline Total costos de producción & \\
\hline Costo mensual & \\
\hline
\end{tabular}

Tabla 12. Especificaciones técnicas de la producción de papa orgánica en colones.

\begin{tabular}{lr}
\hline Total costos de producción & \\
\hline Costo mensual & 73535,00 \\
\hline Área m ${ }^{2}$ & 1000 \\
Duración del ciclo & 4 \\
Rotaciones (anual) & 2 \\
Producción mensual & 1472 \\
\hline
\end{tabular}


En la Tabla 13 se muestran la depreciación de activos como motoguadaña, motocultivador, bomba de motor y bomba de estacionaria.

Tabla 13. Inversión para la producción de papa orgánica.

\begin{tabular}{|c|c|c|c|}
\hline Activos & Costo inversión & Depreciación anual & Depreciación mensual \\
\hline Motocultivador & 450000,00 & 45000 & 3750,00 \\
\hline Motoguadaña & 250000,00 & 25000 & 2083,33 \\
\hline Bomba de motor & 150000,00 & 30000 & 2500,00 \\
\hline Bomba estacionaria & 300000,00 & 60000 & 5000,00 \\
\hline Total & 1150000,00 & 160000,00 & 13333,33 \\
\hline
\end{tabular}

En la Tabla 14 los costos directos se estimaron en mano de obra 4 medios tiempo a la semana o 2 días completos a la semana según necesidad del cultivo, generando un total de 80000 colones mensuales, las semillas necesarias son 7 sacos de $45 \mathrm{~kg}$ para la siembra de los mil metros. Se estimaron los costos indirectos de análisis de suelo, depreciaciones del equipo, y mantenimiento y otros citados como costos indirectos que incluyen depreciación y mantenimiento y los costos administrativos por mes a de persona para la contabilidad.
Tabla 14. Costos directos, indirectos, administrativos de papa orgánica en colones.

\begin{tabular}{lr}
\hline Rubro & Costos directos \\
\hline Mano de obra & 80000,00 \\
Control biológico & 10350,00 \\
Fertilizantes orgánicos & 4795,00 \\
Plántulas/ semillas & 175000,00 \\
\hline Total & 270145,00 \\
\hline Rubro & 15000,00 \\
\hline Análisis de suelo & 13333,33 \\
Depreciación & 5000,00 \\
Mantenimiento & 2000,00 \\
Agua & 20000,00 \\
Combustible & 20000,00 \\
\hline Cajas & 75333,33 \\
\hline Total & 355478,33 \\
\hline Rubro & Costos administrativos \\
\hline Contador & 10000 \\
\hline Total costos de producción & \\
\hline Costo mensual & \\
\hline
\end{tabular}




\section{Lechuga orgánica}

En la Tabla 15 se muestran las especificaciones técnicas para la producción de lechuga orgánica, se estimó para un cultivo de $250 \mathrm{~m}^{2}$ con una producción mensual de 2400 unidades.

En la Tabla 16 se estimaron los costos de depreciación de activos necesarios para la producción como la motoguadaña, motocultivador, la bomba de motor y la bomba de espalda para obtener la depreciación mensual.
Tabla 15. Especificaciones técnicas de la producción de lechuga orgánica.

\begin{tabular}{lr}
\hline Área $\mathrm{m}^{2}$ & 250 \\
\hline Duración del ciclo & $1 \mathrm{mes}$ \\
Rotaciones (anual) & 12 \\
Producción mensual & 2400 \\
\hline
\end{tabular}

Tabla 16. Inversión para la producción de lechuga orgánica en colones.

\begin{tabular}{lccc}
\hline \multicolumn{1}{c}{ Activos } & Costos inversión & Depreciación anual & Depreciación mensual \\
\hline Motocultivador & 450000,00 & 45000 & 3750,00 \\
Motoguadaña & 250000,00 & 25000 & 2083,33 \\
Bomba de motor & 150000,00 & 30000 & 2500,00 \\
Bomba estacionaria & 300000,00 & 60000 & 5000,00 \\
\hline Total & 1150000,00 & 160000,00 & 13333,33 \\
\hline
\end{tabular}

En la Tabla 17 se desglosan los costos de producción, en costos directos se estableció que una persona trabajaría 2 medios días a la semana generando un total de 40000 colones al mes y se usaría 12, 5 bandejas de almacigo de lechuga con 200 plantas cada bandeja para la siembra de $\operatorname{los} 250 \mathrm{~m}^{2}$. Los costos indirectos incluyen la depreciación, análisis de suelo, mantenimiento entre otros desglosados en la tabla y los costos administrativos del contador.
Tabla 17. Costos directos, indirectos, administrativos de lechuga orgánica en colones.

\begin{tabular}{lr}
\hline Rubro & Costos directos \\
\hline Mano de obra & 40000,00 \\
Control biológico & 2587,50 \\
Fertilizantes orgánicos & 1199,00 \\
Almacigo & 37500,00 \\
\hline Total & 81286,50 \\
\hline Rubro & Costos indirectos \\
\hline Análisis de suelo & 15000,00 \\
Depreciación & 13333,33 \\
Mantenimiento & 1000,00 \\
Agua & 500,00 \\
Combustible & 10000,00 \\
Cajas & 10000,00 \\
\hline Total & 49833,33 \\
\hline Rubro & 10000 \\
\hline Contador & 141119,83 \\
\hline Total costos de producción
\end{tabular}




\section{Brócoli orgánico}

La Tabla 18 muestra las especificaciones para el análisis de la producción de brócoli, se estimó para $1500 \mathrm{~m}^{2}$ con una producción de 400 kilos.

En la Tabla 19 se muestran los activos utilizados para la producción y su respectiva depreciación mensual para el motocultivador, motoguadaña, y las bombas de motor y estacionaria.
Tabla 18. Especificaciones técnicas de la producción de brócoli orgánico.

\begin{tabular}{lr}
\hline Área $\mathrm{m}^{2}$ & 1500 \\
\hline Duración del ciclo & 4 meses \\
Rotaciones (anual) & 3 \\
Producción mensual & 400 \\
\hline
\end{tabular}

Tabla 19. Inversión para la producción de brócoli orgánica en colones.

\begin{tabular}{lccc}
\hline \multicolumn{1}{c}{ Activos } & Costo inversión & Depreciación anual & Depreciación mensual \\
\hline Motocultivador & 450000,00 & 45000 & 3750,00 \\
Motoguadaña & 250000,00 & 25000 & 2083,33 \\
Bomba de motor & 150000,00 & 30000 & 2500,00 \\
Bomba estacionaria & 300000,00 & 60000 & 5000,00 \\
\hline Total & 1150000,00 & 160000,00 & 13333,33 \\
\hline
\end{tabular}

La Tabla 20 expone costos directos que cuentan con 3 días de trabajo completo a la semana o bien, con turnos de 6 medios días de trabajo semana. Se determinó un total de 120000 colones mensuales asignados a la mano de obra. Se utilizan mensualmente 8 bandejas de almácigo de brócoli con 200 plantas cada bandeja. Los costos indirectos incluyen servicios, análisis de suelo, depreciación y mantenimiento, además se incluye el costo de administración del contador.
Tabla 20. Costos directos, indirectos, administrativos de brócoli orgánica en colones.

\begin{tabular}{lr}
\hline Rubro & Costos directos \\
\hline Mano de obra & 120000,00 \\
Control biológico & 15525,00 \\
Fertilizantes orgánicos & 7192,00 \\
Almacigo & 40000,00 \\
\hline Total & 182717,00 \\
\hline Rubro & Costos indirectos \\
\hline Análisis de suelo & 15000,00 \\
Depreciación & 13333,33 \\
Mantenimiento & 500,00 \\
Agua & 500,00 \\
Combustible & 10000,00 \\
Cajas & 10000,00 \\
\hline Total & 49333,33 \\
\hline Rubro & 10000 \\
\hline Contador & 242050,33 \\
\hline Total costos de producción
\end{tabular}




\section{Zanahoria en producción convencional}

En la Tabla 21 para la zanahoria convencional se consideró una producción de $250 \mathrm{~m}^{2}$, con una cosecha de 487 kilos.

En la Tabla 22 se desglosan los costos de producción. Los costos para la producción son mensuales. El total de agroquímicos utilizados en valor monetario son de 55737 colones para los $250 \mathrm{~m}^{2}$, además, en agricultura convencional se contratan labores como tractor o horas animales para arar el terreno y crear las hileras para siembra, por lo que generan un costo adicional.
Tabla 21. Especificaciones técnicas de la producción de zanahoria convencional.

\begin{tabular}{lr}
\hline Área $\mathrm{m}^{2}$ & $250 \mathrm{~m}^{2}$ \\
\hline Duración del ciclo & 5 meses \\
Rotaciones (anual) & 2 \\
Producción & 487 \\
\hline
\end{tabular}

Tabla 22. Costos directos e indirectos de zanahoria convencional en colones.

\begin{tabular}{lr}
\hline Rubro & Costos directos \\
\hline Labores contratadas & 10000,00 \\
Labores ordinarias & 40000,00 \\
Fertilizante & 55737,64 \\
Semilla & 14625,00 \\
\hline Total & 120362,64 \\
\hline Rubro & 15000,00 \\
\hline Análisis de suelo & 22600,00 \\
Equipo de protección & 5000,00 \\
Mantenimiento & 20000,00 \\
Combustible & 7500,00 \\
Depreciación & 1000,00 \\
\hline Agua & 71100,00 \\
\hline Total & 191462,64 \\
\hline Total costos de producción & \\
\hline Costo mensual & \\
\hline
\end{tabular}

las Buenas Prácticas Agrícolas (BPA), debido a que los agroquímicos llegan a generar gran cantidad de problemas en la salud de los trabajadores con su uso constante y el paso del tiempo. La depreciación se realizó de manera mensual y se incluyeron el uso de bomba de espalda y bomba estacionaria, los vehículos de los productores encuestados ya se encontraban completamente depreciados por lo que no se incluyeron en la depreciación, sin embargo, como se observó en el caso de los productores orgánicos se incluyó 
el marchamo y cambio de aceite en el mantenimiento, además del uso de mallas para guardar y entregar producto, de uso muy utilizado en producción convencional. En producción convencional no se tiene gasto administrativo debido a que los productores convencionales al no llevar controles tan rigurosos no cuentan con un contador que les lleve las cuentas, por lo que no incurren en este costo.

En la Tabla 24 se presentan los costos directos e indirectos de producción convencional. En labores ordinarias se cuenta con 2 días a la semana de trabajo completo o 4 medios días según necesidad del cultivo; se contratan labores para arar el cultivo y la cantidad de fertilizante utilizado para los $500 \mathrm{~m}^{2}$ es de 237045,40 colones mensuales. En la parte de mantenimiento se contemplan los gastos de cambio de aceite y marchamo del vehículo, aunque este no cuente en la tabla de depreciación debido a que está completamente depreciado. En depreciación se considera el uso de bomba estacionaria y bomba de espalda necesaria para la producción.

\section{Apio en producción convencional}

En la Tabla 23 se encuentran las especificaciones del estudio de apio para una producción convencional de $500 \mathrm{~m}^{2}$ con una producción mensual de 3000 plantas.

Tabla 23. Especificaciones técnicas de la producción de apio convencional.

\begin{tabular}{lr}
\hline Área $\mathrm{m}^{2}$ & 500 \\
\hline Duración del ciclo & 4 meses \\
Rotaciones (anual) & 3 \\
Producción mensual & 3000 \\
\hline
\end{tabular}

Tabla 24. Costos directos e indirectos de apio convencional en colones.

\begin{tabular}{lr}
\hline Rubro & Costos directos \\
\hline Labores contratadas & 20000,00 \\
Labores ordinarias & 80000,00 \\
fertilizante & 237045,40 \\
semilla & 52500,00 \\
\hline Total & 389545,40 \\
\hline Rubro & 15000,00 \\
\hline Análisis de suelo & 5000,00 \\
Mantenimiento & 1000,00 \\
Agua & 11000,00 \\
Combustible & 7500,00 \\
Depreciación & 39500,00 \\
\hline Total & 429045,40 \\
\hline Total costos de producción & \\
\hline Costo mensual & \\
\hline
\end{tabular}




\section{Culantro en producción convencional}

En la Tabla 25 se encuentran las especificaciones del diagnóstico para la producción de culantro convencional. El estudio del culantro es de $100 \mathrm{~m}^{2}$ con una cosecha de 3000 rollos de producción mensual.

En la Tabla 26 se muestra un desglose de los costos directos e indirectos de producción mensual. Se estima labores ordinarias de una persona 2 medios días a la semana, más labores contratadas de tractor o buey. Para la producción de $100 \mathrm{~m}^{2}$ se estima un costo en fertilizante de 7240 colones mensuales, más el costo de semilla para el área de estudio con un costo de 1375 colones. En costos indirectos se estimó la depreciación para una bomba de espalda y una bomba estacionaria necesaria para la producción. Además, se consideró el uso de combustible mensual para trasladar insumos y productos.

\section{Papa en producción convencional}

En la Tabla 27 se desglosan las especificaciones técnicas del cultivo de papa en método de producción convencional, el área para el estudio de la papa fue de $1000 \mathrm{~m}^{2}$ con una cosecha de $2290 \mathrm{~kg}$.
Tabla 25. Especificaciones técnicas de la producción de culantro convencional.

\begin{tabular}{lr}
\hline Área $\mathrm{m}^{2}$ & 100 \\
\hline Duración del ciclo & 2 meses \\
Rotaciones (anual) & 6 \\
Producción mensual & 3000 \\
\hline
\end{tabular}

Tabla 26. Costos directos e indirectos de culantro convencional en colones.

\begin{tabular}{lr}
\hline Rubro & Costos directos \\
\hline Labores contratadas & 10000,00 \\
Labores ordinarias & 40000,00 \\
Fertilizante & 7240,00 \\
Semilla & 1375,00 \\
\hline Total & 58615,00 \\
\hline Rubro & 15000,00 \\
\hline Análisis de suelo & 5000,00 \\
Mantenimiento & 7500,00 \\
Depreciación & 10000,00 \\
Combustible & 7500,00 \\
\hline Depreciación & 45000,00 \\
\hline Total & 103615,00 \\
\hline Total costos de producción &
\end{tabular}

Tabla 27. Especificaciones técnicas de la producción de papa convencional.

\begin{tabular}{lr}
\hline Área $\mathrm{m}^{2}$ & 1000 \\
\hline Duración del ciclo & 4 \\
Rotaciones (anual) & 2 \\
Producción & 2990 \\
\hline
\end{tabular}


En la Tabla 28 se puede observar el desglose total de los costos directos e indirectos. La papa es un cultivo con altos costos de producción. Para la aplicación de fertilizantes se estimó un valor económico de 262565 colones para los $1000 \mathrm{~m}^{2}$; se identificaron labores contratadas por 20000 colones para la preparación del terreno, en labores ordinarias se valoró considerando el uso de mano de obra por 2 días a la semana o 4 medios días según necesidades del cultivo generando un costo de 80000 colones mensuales. En los costos indirectos en el mantenimiento se consideró el marchamo del vehículo de la finca el cual ya se encuentra depreciado en su totalidad, y el cambio de aceite, además se estima el uso de malla y boquillas para las bombas, en depreciaciones, se deprecio la bomba de espalda y la bomba estacionaria de manera mensual.

Tabla 28. Costos directos e indirectos de papa convencional en colones.

\begin{tabular}{lr}
\hline Rubro & Costos directos \\
\hline Labores contratadas & 20000,00 \\
Labores ordinarias & 80000,00 \\
Fertilizante & 262565,00 \\
Semilla & 135000,00 \\
\hline Total & 497565,00 \\
\hline Rubro & 15000,00 \\
\hline Análisis de suelo & 7500,00 \\
Depreciación & 5000,00 \\
Mangueras, boquillas, mallas & 20000,00 \\
\hline Combustible & 47500,00 \\
\hline Total & 545065,00 \\
\hline Total costos de producción & \\
\hline Costo mensual & \\
\hline
\end{tabular}

\section{Lechuga en producción convencional}

En la Tabla 29 se muestran las especificaciones técnicas para el estudio de lechuga convencional, se realizó en $250 \mathrm{~m}^{2}$ con una cosecha de 3900 unidades.

Tabla 29. Especificaciones técnicas de la producción de lechuga convencional.

\begin{tabular}{lr}
\hline Área $\mathrm{m}^{2}$ & 250 \\
\hline Duración del ciclo & $1 \mathrm{mes}$ \\
Rotaciones (anual) & 12 \\
Producción mensual & 3900 \\
\hline
\end{tabular}

En la Tabla 30 se desglosan los costos directos e indirectos de producción. A partir del área estudiada, se identificó mano de obra de una persona 2 medios días a la semana, generando un costo mensual de 40000 colones. Entre los costos indirectos tenemos el análisis de suelo, el mantenimiento que incluye cambio de aceite y marchamo, se toma en cuenta los costos de combustible necesario para traslado de insumos.

Tabla 30. Costos directos e indirectos de lechuga convencional en colones.

\begin{tabular}{lr}
\hline Rubro & Costos directos \\
\hline Labores contratadas & 10000,00 \\
Labores ordinarias & 40000,00 \\
Fertilizante & 37068,00 \\
Almacigo & 47250,00 \\
\hline Total & 134318,00 \\
\hline Rubro & 15000,00 \\
\hline Análisis de suelo & 5000,00 \\
Mantenimiento & 5000,00 \\
Agua & 10000,00 \\
\hline Combustible & 35000,00 \\
\hline Total & 169318,00 \\
\hline Total costos de producción & \\
\hline Costo mensual &
\end{tabular}




\section{Brócoli en producción convencional}

Para el análisis del cultivo de brócoli se realizó en $1500 \mathrm{~m}^{2}$ con una cosecha mensual de $1800 \mathrm{~kg}$. En la Tabla 31 se muestra el desglose de las especificaciones técnicas.

En la Tabla 32 se desglosan los costos directos e indirectos de producción. El brócoli requiere de muchos cuidados, fumigaciones, insecticidas y fertilizantes, por lo que se estimó mano de obra de una persona 3 días a la semana durante un mes, generando un costo mensual de 120000 colones, todos los productores convencionales realizan labores contratadas para la preparación del terreno, para los $1500 \mathrm{~m}^{2} \mathrm{de}$ brócoli se estima un costo de labores contratadas de 25000 colones. Debido a los cuidados y la gran cantidad de plagas que afectan al brócoli el uso de fertilizantes es un impacto significativo en el factor económico por lo que los costos de fertilización son de 220113 colones para los $1500 \mathrm{~m}^{2}$. Entre los costos indirectos se estiman el análisis de suelo, mantenimiento bajo los criterios anteriormente mencionados, depreciación de equipo mensual de bomba de espalda y bomba estacionaria.

\section{Comparación entre producción convencional y orgánica}

A continuación, se presenta la comparación entre producción orgánica y producción convencional estimando los costos mensuales de producción según área de siembra y el costo unitario de cada producto según cosecha. Además, se establecen la utilidad que generan los
Tabla 31. Especificaciones técnicas de la producción de brócoli convencional.

\begin{tabular}{lr}
\hline Área $\mathrm{m}^{2}$ & 1500 \\
\hline Duración del ciclo & $1 \mathrm{mes}$ \\
Rotaciones (anual) & 12 \\
Producción mensual & 1800 \\
\hline
\end{tabular}

Tabla 32. Costos directos e indirectos de brócoli convencional en colones.

\begin{tabular}{lr}
\hline Rubro & Costos directos \\
\hline Labores contratadas & 25000,00 \\
Labores ordinarias & 120000,00 \\
Fertilizante & 220113,00 \\
Almácigo & 29250,00 \\
\hline Total & 394363,00 \\
\hline Rubro & 15000,00 \\
\hline Análisis de suelo & 5000,00 \\
Mantenimiento & 5000,00 \\
Agua & 20000,00 \\
Combustible & 45000,00 \\
\hline Total & 439363,00 \\
\hline Total costos de producción & \\
\hline Costo mensual & \\
\hline
\end{tabular}

productos y los indicadores financieros de costobeneficio y margen de utilidad. El costo/ beneficio también se conoce como índice neto de rentabilidad y mide el grado de desarrollo de un proyecto, se obtiene al dividir la utilidad entre costos totales de producción, la interpretación del índice es que si el índice es igual a uno, no se están generando beneficios o riqueza por lo cual 
es indiferente el proyecto, mientras si el indicador es mayor a uno significa que los ingresos son superiores a los egresos, lo que representa que el proyecto está generó ingresos.

El índice de margen de ganancia indica la rentabilidad de un producto, se expresa como un porcentaje, mientras más elevado sea el porcentaje, más rentable es el producto o el proyecto, se obtiene al restar a las ventas los costos de producción y se dividen entre las ventas y se multiplica por 100, y como porcentaje, el margen de ganancias bruto.

\section{Zanahoria}

Tal como se muestra en la Tabla 33 el costo de producción mensual en la producción convencional es mayor al de producción orgánica, esto debido al mayor uso de fertilizantes y su costo, además el costo unitario por kilo de zanahoria es menor en la producción orgánica que en la producción convencional, por lo que el costo de un kilo de zanahoria en producción convencional es 114, 1 colones mayor al costo de producción convencional.

Tabla 33. Costo mensual por metro cuadrado y costo unitario según tipo de producción para zanahoria en colones, 2019.

\begin{tabular}{cccc}
\hline Tipo de producción & Costo mensual & Costo $^{2}$ & Costo unitario \\
\hline Orgánica & 111620,08 & 446,48 & 279,05 \\
Convencional & 191462,64 & 765,85 & 393,15 \\
\hline
\end{tabular}

En la Tabla 34 se establece la utilidad neta en ambas producciones y los indicadores financieros de costo beneficio y margen de ganancias explicados anteriormente.

Tabla 34. Utilidad neta e indicadores financieros para zanahoria en colones, 2019.

\begin{tabular}{lccrrr}
\hline $\begin{array}{c}\text { Tipo } \\
\text { de producción }\end{array}$ & Ventas & Costos de producción & UN & C/B & $\begin{array}{c}\text { Margen de } \\
\text { ganancia }\end{array}$ \\
\hline Orgánica & 280000,00 & 111620,08 & 168379,92 & 1,51 & $60,14 \%$ \\
Convencional & 243500,00 & 191462,64 & 52037,36 & 0,27 & $21 \%$ \\
\hline
\end{tabular}

En la producción orgánica el precio de venta por kilo de zanahoria es de 700 colones mientas el precio en producción convencional es de 500 colones, por lo que aunque en ambos casos se generan ganancias en la producción convencional el costo/ beneficio es menor a uno lo que implica que el proyecto no es tan rentable, sin embargo, el margen de ganancia es de un $21 \%$, este margen tan bajo se puede deber a que los costos de producción y las ventas del producto son muy similares lo que genera que el margen de ganancia y costo beneficio disminuya.

\section{Apio}

En la Tabla 35 se observa que los costos de producción mensuales en el caso de la producción convencional son 279 637,07 colones mayores al costo mensual de producción orgánica del apio, con un costo de producción convencional de más del $50 \%$ que la producción orgánica, sin embargo, en los costos unitarios la diferencia por planta es de 43, 41 colones, esto se debe que aunque los costos de producción convencional son mayores, la cantidad de producto cosechado, incide en la reducción el costo unitario. 
Tabla 35. Costo mensual, por metro cuadrado y costo unitario según tipo de producción para apio en colones, 2019.

\begin{tabular}{cccc}
\hline Tipo de producción & Costo mensual & Costo $/ \mathrm{m}^{2}$ & Costo unitario \\
\hline Orgánica & 149408,33 & 597,63 & 99,61 \\
Convencional & 429045,40 & 858,09 & 143,02 \\
\hline
\end{tabular}

En la Tabla 36 se observa que el margen de ganancias es superior en un $16,6 \%$ en producción orgánica, esto se debe al precio de los productos y la cantidad cosechada. El producto orgánico generó 960 matas mensuales a un precio de 500 colones, mientras la producción convencional cosecho 3000 matas a 300 colones. Se muestra así que, aunque la producción orgánica vende a mayor precio, la cantidad reducida de producción disminuye sus ganancias, pero al ser sus costos de producción más bajo logra obtener mayor ganancia.

Tabla 36. Utilidad neta e indicadores financieros para apio en colones, 2019.

\begin{tabular}{cccccc}
\hline Tipo de producción & Ventas & Costos de producción & UN & C/B & Margen de ganancia \\
\hline Orgánica & 480000,00 & 149408,33 & 330591,67 & 2,21 & $68,9 \%$ \\
Convencional & 900000,00 & 429045,40 & 470954,60 & 1,10 & $52,3 \%$ \\
\hline
\end{tabular}

Sin embargo, debido a los costos de producción en ambos sistemas, se muestra que el costo beneficio y el margen de ganancia son mucho mayor en la producción orgánica, por lo que el costo beneficio demuestra que por cada colon invertido genera una ganancia de 1,21 colones, mientras que evaluando ventas y costos de la producción la orgánica obtuvo un margen de ganancia de un $68,9 \%$.

Según indicadores ambos tipos de producción generan ganancias, sin embargo, debido a los altos costos de producción en convencional, por colón invertido según indicador de costobeneficio se obtiene una ganancia de 0,10 colones y según ventas y costos el margen de ganancias obtenido es de un $52,3 \%$.

\section{Culantro}

En la Tabla 37 se muestra el costo mensual de producción de culantro, en producción convencional el costo es superior por 30080 colones que en producción orgánica, sin embargo, los costos unitarios por rollo culantro es menor en 9,57 colones en producción convencional y esto se debe a que en producción convencional se cosechan 3000 rollos de culantro que se distribuyen en mayor cantidad de unidades que en producción orgánica que se cosechan de manera mensual 1667 rollos, lo que hace que el costo unitario sea mayor. 
Tabla 37. Costo mensual, por metro cuadrado y costo unitario según tipo de producción para culantro en colones, 2019.

\begin{tabular}{cccc}
\hline Tipo de producción & Costo mensual & Costo $/ \mathrm{m}^{2}$ & Costo unitario \\
\hline Orgánica & 73535,00 & 735,35 & 44,11 \\
Convencional & 103615,00 & 1036,15 & 34,54 \\
\hline
\end{tabular}

En la Tabla 38 se muestra la utilidad neta de ambos tipos de producción, en la producción convencional la utilidad genera más ingresos debido a la cantidad cosechada y a un precio de 150 colones el rollo, en la orgánica el precio del rollo orgánico sale en 200 colones, lo cual no es gran la diferencia con el precio convencional que se vende a 150 colones, pero la producción obtenida disminuyo casi en un $50 \%$ en producción orgánica.

Tabla 38. Utilidad neta e indicadores financieros para culantro en colones 2019.

\begin{tabular}{cccccc}
\hline Tipo de producción & Ventas & Costos de producción & UN & C/B & Margen de ganancia \\
\hline Orgánica & 333400,00 & 73535,00 & 259865,00 & 3,53 & $77,9 \%$ \\
Convencional & 450000,00 & 103615,00 & 346385,00 & 3,34 & $77,0 \%$ \\
\hline
\end{tabular}

En los indicadores financieros se muestra que aun con la variación entre ingresos el margen de ganancias y el costo beneficio se mantienen muy similares en ambos métodos de producción, esto se justifica con la diferencia en costos de producción de los cultivos y la diferencia entre el precio de venta.

\section{Papa}

En la Tabla 39 se observa los costos de producción según su tipo, se puede percibir que ambos costos mensuales de producción son elevados, sin embargo, son más altos para producción convencional en 189 586,67 colones en comparación con la orgánica, en la papa el costo de la semilla es un costo importante y los fertilizantes y cantidad de los mismos se aplican con mayor frecuencia, por lo que se elevan los cotos en ambas producciones, sin embargo, el costo unitario es más alto para la producción orgánica en 59,19 colones debido a la disminución en la producción, por lo que en convencional se cosechan $2990 \mathrm{~kg}$, mientras en producción orgánica se obtienen $1472 \mathrm{~kg}$. Por lo que los costos en la producción convencional se disuelven en más unidades, lo que genera que el cultivo convencional tenga un costo de producción unitario menor.

Tabla 39. Costo mensual, por metro cuadrado y costo unitario según tipo de producción para papa en colones, 2019.

\begin{tabular}{cccc}
\hline Tipo de producción & Costo mensual & Costo $/ \mathrm{m}^{2}$ & Costo unitario \\
\hline Orgánica & 355478,33 & 355,48 & 241,49 \\
Convencional & 545065,00 & 545,07 & 182,30 \\
\hline
\end{tabular}


En la Tabla 40 se presenta la utilidad neta de los tipos de producción, en producción orgánica se reflejan mayores utilidades con un aumento de 304 586,67 colones en relación con la utilidad de la producción convencional, aun con la disminución de la producción en casi un $50 \%$ en producción orgánica pero esto se justifica debido al precio de venta, en producción convencional se vende a 700 colones el kilo, mientras en producción orgánica el kilo de papa se vende a 1500 colones, con un $114 \%$,mayor al precio de producción convencional, lo que genera que las ganancias en producción orgánica sean mayores.

Tabla 40. Utilidad neta e indicadores financieros para papa en colones, 2019.

\begin{tabular}{cccccc}
\hline Tipo de producción & Ventas & Costos de producción & UN & C/B & Margen de ganancia \\
\hline Orgánica & 2208000,00 & 355478,33 & 1852521,67 & 5,21 & $84 \%$ \\
Convencional & 2093000,00 & 545065,00 & 1547935,00 & 2,84 & $74 \%$ \\
\hline
\end{tabular}

Según los indicadores, el costo beneficio de producción orgánica es de 5,21 lo que implica que por cada colon invertido se tiene una ganancia de 4,21 colones y un margen de ganancia de un $84 \%$ y en producción convencional al ser los costos mayores a producción orgánica genera que los ingresos disminuyan al igual que los indicadores, por lo que por cada colon invertido en producción convencional se obtiene una ganancia de 1,84 colones, mientras que el margen de ganancia es de $74 \%$.

\section{Lechuga}

En la Tabla 41 se muestran los costos de producción según tipo de producción orgánico o convencional, en la producción convencional los costos son mayores en 28 198,17 colones, sin embargo, debido a la producción de 3900 unidades los costos se diluyen y generan costos unitarios de producción menores en 15,39 colones con respecto a la producción orgánica.

Tabla 41. Costo mensual, por metro cuadrado y costo unitario según tipo de producción para Lechuga en colones, 2019.

\begin{tabular}{cccc}
\hline Tipo de producción & Costo mensual & Costo/m $\mathrm{m}^{2}$ & Costo unitario \\
\hline Orgánica & 141119,83 & 564,48 & 58,80 \\
Convencional & 169318,00 & 677,27 & 43,41 \\
\hline
\end{tabular}

En producción orgánica, aunque los costos de producción son menores en un $16,5 \%$, el costo unitario es mayor debido a que la producción disminuye a 2400 unidades, generando que el costo unitario sea de 58,8 colones.

En la Tabla 42 se muestra que las utilidades netas son muy similares para ambos cultivos, la producción orgánica vende a 150 colones la unidad y cosecha 2400 plantas, mientras en producción convencional se vende a 100 colones la unidad y se cosechan 3900 plantas, que compensan en cantidad, el precio. El índice costo beneficio es muy similar para ambos tipos de producción y ambos son mayores a uno, lo que implica que genera beneficios y el producto es rentable y el margen de ganancias para la producción convencional que sus costos de producción son mayores es de un $57 \%$ mientas para producción orgánica es de un $61 \%$. 
Tabla 42. Utilidad neta e indicadores financieros para lechuga en colones, 2019.

\begin{tabular}{cccccc}
\hline Tipo de producción & Ventas & Costos de producción & UN & C/B & Margen de ganancia \\
\hline Orgánica & 360000,00 & 141119,83 & 218880,17 & 1,55 & $61 \%$ \\
Convencional & 390000,00 & 169318,00 & 220682,00 & 1,30 & $57 \%$ \\
\hline
\end{tabular}

\section{Brócoli}

En la Tabla 43 se nota que el diferencia entre costo de producción para producción convencional es de un 44,9\% mayor a la producción orgánica, sin embargo, los costos unitarios de producción orgánica son un $148 \%$ mayores a los costos unitarios de producción convencional, esto debido a que en producción convencional se cosechan $1800 \mathrm{~kg}$ a un precio de 500, mientras en producción orgánica se cosechan $400 \mathrm{~kg}$ a un precio de 1500 colones por lo que aunque en producción orgánica se triplique el precio este no compensa la baja en la producción.

Tabla 43. Costo mensual, por metro cuadrado y costo unitario según tipo de producción para Brócoli en colones, 2019.

\begin{tabular}{cccc}
\hline Tipo de producción & Costo mensual & Costo $/ \mathrm{m}^{2}$ & Costo unitario \\
\hline Orgánica & 242050,33 & 161,37 & 605,13 \\
Convencional & 439363,00 & 292,91 & 244,09 \\
\hline
\end{tabular}

En la Tabla 44 se muestra que las utilidades para producción orgánica son menores en 102 687,33 colones que para producción convencional, sin embargo, debido a los costos de producción los índices son mejores para la producción orgánica que convencional.

Tabla 44. Utilidad neta e indicadores financieros para brócoli en colones, 2019.

\begin{tabular}{lccccc}
\hline Tipo de producción & Ventas & Costos de producción & UN & C/B & \multicolumn{2}{c}{ Margen de ganancia } \\
\hline Orgánica & 600000,00 & 242050,33 & 357949,67 & 1,48 & $60 \%$ \\
Convencional & 900000,00 & 439363,00 & 460637,00 & 1,05 & $51 \%$ \\
\hline
\end{tabular}

El indicador de costo beneficio es de 1,48 para producción orgánica lo que implica que por cada colon invertido se genera una ganancia de 0,48 colones y un margen de ganancia de un $60 \%$ debido a la baja de los costos de producción y elevados precios de venta, en producción convencional se genera una ganancia de 0,5 por cada colon invertido y un margen de ganancia de un $51 \%$ debido a los altos costos de producción y un precio de venta más bajo. Sin embargo, son positivos en ambos casos por lo que el proyecto es viable en los 2 tipos de producción.

En la Tabla 45 se muestran el resumen de los costos de producción convencional y orgánico para los 6 productos estudiados en el diagnostico con la deferencia en colones y porcentual de los costos de producción. La tabla muestra el apio es el producto con mayor diferencia en los costos de producción con una diferencia de 279 637,07 colones, que representa el $65,18 \%$ sobre los costos de producción convencional, mientras la 
diferencia representa la menor diferencia entre costos de producción orgánico y convencional con 28 198, 17 colones que representa el 16, 65\% sobre costos de producción convencional.

Tabla 45. Costos de producción convencional y orgánico en colones, octubre 2019.

\begin{tabular}{lcccc}
\hline Producto & $\begin{array}{c}\text { Costo } \\
\text { convencional }\end{array}$ & $\begin{array}{c}\text { Costo } \\
\text { orgánico }\end{array}$ & $\begin{array}{c}\text { Diferencia de } \\
\text { costo de producción } \\
\text { (convencional -orgánico) }\end{array}$ & $\begin{array}{c}\text { Diferencia } \\
\text { porcentual }\end{array}$ \\
\hline Zanahoria & 191462,64 & 111620,08 & 79842,56 & $41,70 \%$ \\
Apio & 429045,40 & 149408,33 & 279637,07 & $65,18 \%$ \\
Culantro & 103615,00 & 73535,00 & 30080 & $29,03 \%$ \\
Papa & 545065,00 & 355478,33 & 189586,67 & $34,78 \%$ \\
Lechuga & 169318,00 & 141119,83 & 28198,17 & $16,65 \%$ \\
Brócoli & 439363,00 & 242050,33 & 197312,67 & $44,91 \%$ \\
\hline
\end{tabular}

En la Figura 1 se muestra de manera visual los costos de producción para cada uno de los diferentes cultivos estudiados en producción convencional y orgánica.

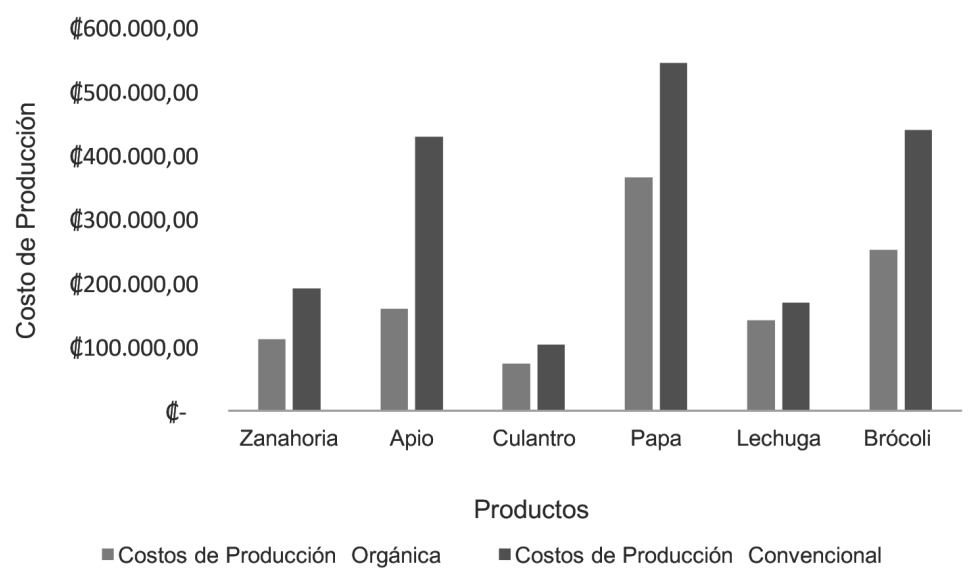

Figura 1. Costo de producción para cultivo orgánico y convencional según producto, 2019.

Se pueden observar que en el caso del apio los costos de producción presentan una diferencia significativa, los costos para producción convencional son 279 637,07 mayores que en producción orgánica, en el caso de papa y brócoli, ambos costos son elevados en ambas producciones, con diferencias de 189586,67 y 187312,67 colones respectivamente. En el caso de la zanahoria, culantro y lechuga presentan costos de producción bajos con diferencias entre los costos de producción de $\mathbb{C} 79842,56, \mathbb{C} 30080$ y $\mathbb{C 2 8} 198,17$ respectivamente, con un costo de producción convencional superior.

Se puede resumir que entre los 6 productos estudiados la papa presenta los mayores costos de producción seguido de brócoli y apio mientras el culantro fue el cultivo con menores costos de producción. 
En general los resultados de la investigación evidencian que la producción convencional como actividad comercial, se fundamenta en criterios de productividad, (unidades producidas/ área) con importante demanda de insumos externos y algún tipo de tecnología, mientras que la producción orgánica, expone costos con baja dependencia de insumos externos, con prácticas que consideran sustantivamente, favorecer las condiciones agroecológicas, la salud de las personas productoras y a la vez de quienes consumen sus productos. $\mathrm{Al}$ respecto se menciona que los productores orgánicos aspiran a optimizar la calidad en todos los aspectos de la agricultura y el ambiente Dumani (2007).

\section{Punto de equilibrio unitario y margen de ganancia}

La Tabla 46 muestra los puntos de equilibrio unitario en colones de los 6 productos analizados, tanto en producción orgánica como en producción convencional. Se estimó al dividir los costos totales de producción de cada producto entre las unidades producidas. En economía el punto de equilibrio es un indicador en el que los costos, gastos y los ingresos son iguales: no hay pérdida neta ni ganancia; es expresado en volumen de producción y ventas, donde las ventas de productos necesariamente cubren los costos totales incurridos, con el fin de identificar la igualdad de estas cuatro variables, las mismas que son cantidades, precios, costo variable unitario y costos fijos Fulton y Quiroz (2017). En la medida que el precio unitario de ventas supere este punto se obtendrán utilidades, si el nivel de ventas es inferior al punto de equilibrio la empresa ocasionará pérdidas Peña y Rodríguez (2018).

Tabla 46. Resumen comparativo punto de equilibrio, precios de venta, y margen de ganancia por actividad.

\begin{tabular}{|c|c|c|c|c|c|c|c|}
\hline \multirow[b]{2}{*}{ Producto } & \multirow[b]{2}{*}{ Unidad } & \multicolumn{3}{|c|}{ Producción orgánica } & \multicolumn{3}{|c|}{ Producción convencional } \\
\hline & & $\begin{array}{c}\text { Precio } \\
\text { venta } \\
\text { unitario }\end{array}$ & $\begin{array}{c}\text { Punto equilibrio } \\
\text { unitario }\end{array}$ & $\begin{array}{l}\text { Margen de } \\
\text { ganancia }\end{array}$ & $\begin{array}{c}\text { Precio } \\
\text { venta } \\
\text { unitario }\end{array}$ & $\begin{array}{c}\text { Punto equilibrio } \\
\text { unitario }\end{array}$ & $\begin{array}{c}\text { Margen de } \\
\text { ganancia }\end{array}$ \\
\hline Zanahoria & Kilos & 700 & 279,05 & $60,1 \%$ & 500 & 393,15 & $21,4 \%$ \\
\hline Apio & Mata & 500 & 155,63 & $68,9 \%$ & 300 & 143,02 & $52,3 \%$ \\
\hline Culantro & Rollo & 200 & 44,11 & $77,9 \%$ & 150 & 34,54 & $77,0 \%$ \\
\hline Papa & Kilo & 1500 & 241,49 & $83,9 \%$ & 700 & 182,3 & $74,0 \%$ \\
\hline Lechuga & Unidad & 150 & 58,8 & $60,8 \%$ & 100 & 43,41 & $56,6 \%$ \\
\hline Brócoli & Kilo & 1500 & 605,13 & $59,7 \%$ & 500 & 244,09 & $51,2 \%$ \\
\hline
\end{tabular}

Como ejemplo, se observa que la zanahoria tiene un punto de equilibrio de 279,05 colones. Este valor cubre los costos de producción de cosechar un kilo de zanahoria. En producción orgánica el kilo de zanahoria se vendió en 700 colones, por lo que, al cubrir los costos con
279,05 colones, el productor tuvo un margen de ganancia del $60,1 \%$ por kilo vendido. En el caso de la zanahoria en producción convencional, esta se vendió en 500 colones, pero sus costos de producción fueron mayores que en producción orgánica y su cosecha mayor, por lo que los costos 
de producción unitarios son de 393,15 colones, obtenidos de la división entre la producción de 487 kilos de zanahoria y los costos totales asociados, presentando este costo unitario su punto de equilibrio, con un margen de ganancia del $21,4 \%$ por kilo vendido. Situación que se repite con las especificaciones requeridas, con los demás productos mostrados en la tabla.

Los 6 productos analizados en ambos sistemas de producción fueron vendidos a precios mayores que sus puntos de equilibrio, lo que implica que los productores lograron cubrir los costos de producción y además generaron un margen de ganancia por cada producto vendido.

Se evidenció que la actividad agrícola en general, presenta un faltante de estructuras de costos, aspecto evidenciado por FAO en el 2010 y que aún se mantiene. Ese contenido es señalado como un requerimiento para las actividades del sector y fundamental para la ejecución de las Buenas Prácticas Agrícolas (BPA). No obstante, para todos los casos, se logró determinar el dato de costo de producción unitario, el cual toma en cuenta los costos directos e indirectos y aportes de organizaciones nacionales o internacionales para el desarrollo de las actividades. También se constató que desde décadas atrás los esfuerzos por unirse entre productores orgánicos, ha sido imprescindible para alcanzar propósitos comunes, en particular certificaciones.

En términos generales se comprobó que productores orgánicos venden en ferias del agricultor o puntos de venta; además cultivan pequeñas cantidades de hortalizas, aunque si diversidad de ellas por área cultivada. En cuanto a la comercialización de estos últimos, Barquero (2016) alude que, de la producción orgánica destinada al mercado interno, un $32 \%$ se vende en ferias, un $20 \%$ a intermediarios y un $15 \%$ a restaurantes y hoteles. El restante 33\% se reparte en partes iguales ( $11 \%$ cada uno) entre supermercados, puntos de venta y mercado convencional. Referente a los precios de venta, Sánchez (2019) señala que el precio de los productos orgánicos es superior a sus equivalentes producidos de forma convencional y hace referencia con ello a los elevados costos de producción a los que además se les adiciona el pago por la certificación que, influye en el precio final.

Relativo a la escala de producción, Camacho et al. (2015) expusieron un análisis de una muestra de 30 productores orgánicos en Costa Rica, de los cuales el 70\% estaban certificados. Identificaron a la vez, que los considerados pequeños y medianos productores conforman un $73 \%$ que cultiva en un área inferior a 1,0 ha, mientras que el restante $27 \%$ dispone de más de 1,0 ha, pero menos de 3,0 ha, mientras que los productores con producción bajo el régimen convencional se expanden en mayores cantidades de terreno con un único producto o monocultivo.

\section{CONCLUSIONES}

Durante el período de estudio se evidenció que los productos orgánicos tienen un mayor precio de venta, sin embargo, los productores reciben menos beneficio económico. Lo anterior obedece a la escala de producción que deriva un menor volumen de cosecha por área.

Las actividades con prácticas convencionales expusieron costos específicos superiores, asignables a la demanda y compra de insumos externos y utilización de métodos de tránsito y rodaje de maquinaria, aunque los costos unitarios por el volumen generado en las áreas de producción son menores, excepto para la zanahoria convencional.

Se determinó que en la actividad orgánica, los costos en la producción comparativamente disminuyen, ya que propone baja dependencia de compra de insumos externos pues son generados fundamentalmente en la propia finca del productor, quien promueve prácticas que sugieren la salud del agroecosistema, la biodiversidad y los ciclos biológicos. Sin embargo, por aspectos de productividad (producción/área cultivada) se derivan costos unitarios mayores, que los productores compensan por su oferta más limitada, con mayores precios de venta por unidad comercializada. 


\section{RECOMENDACIONES}

Se recomienda un estudio mercadológico que complemente esta investigación, con el fin de analizar variables de diferenciación que también podrían incidir en los precios de venta de las hortalizas para ambos tipos de productos.

Se recomienda también, considerar espacios para la educación, capacitación e implementación de programas informáticos de estructuras de costos ajustados a las necesidades específicas de los pequeños productores agrícolas. Así se promueve la sistematización de los datos y se procuraría reducir el tiempo de trabajo contable, además favorecería la toma de decisiones y la anticipación de requerimientos para las actividades productivas.

\section{RECONOCIMIENTO}

El estudio se dedica a los agricultores de la zona de Cartago que participaron en esta investigación con su tiempo, paciencia y generosidad que les caracteriza. A ellos que salen todos los días a trabajar, para alimentar a su nación.

\section{LITERATURA CITADA}

Barquero, M. 2016. Terrenos orgánicos en Costa Rica repuntaron en dos últimos años (en línea). La Nación. Consultado 19 mar. 2018. Disponible en https://www.nacion.com/economia/agro/terrenosorganicos-en-costa-rica-repuntaron-en-dos-ultimosanos/6652KW7OSJBOZFCGANEUYMNQVQ/story/

Calleja, F. 2013. Costos. 2 ed. México, Pearson Educación y Universidad. $465 \mathrm{p}$.

Camacho, M; Arauz, K; Barboza, N; Martínez, H; Arias, J. 2015. Caracterización de productores de hortalizas orgánicas distribuidas en la Gran Área Metropolitana (GAM). Agronomía Costarricense 39(2):131-142.

Código de Trabajo Costa Rica. 1995. Capítulo octavo del régimen de los servidores del estado y sus instituciones (en línea). Consultado 04 nov. 2019. Disponible en http://www.ilo.org/dyn/natlex/docs/ WEBTEXT/44102/65002/S95CRI02.htm

Dumani, M. 2007. Agricultura orgánica y seguridad alimentaria y nutricional (en línea). Revista Avances en Seguridad Alimentaria y Nutricional p. 30-40. Consultada 25 may 2018. Disponible en http://www. kerwa.ucr.ac.cr/bitstream/handle/10669/13398/16212440-2-PB.pdf?sequence $=1 \&$ isAllowed $=\mathrm{y}$

Escobar, H. 2003. Análisis de costos para hortalizas ecológicas. Bogotá, Colombia, Fundación Universidad de Bogotá. 40 p.

FAO (Organización de las Naciones Unidas para la Alimentación y la Agricultura). 2018. Preguntas frecuentes sobre agricultura orgánica (en línea). Consultado 24 feb. 2018. Disponible en http://www. fao.org/organicag/oa-faq/oa-faq5/es/

Fulton, TZ; Quiroz, E. 2017. El punto de equilibrio como una herramienta de planificación financiera y su incidencia en el estado de resultado integral. Revista Observatorio de la Economía Latinoamericana, Ecuador. Consultado 04 de ene. 2020. Disponible en https://www.eumed.net/cursecon/ecolat/ec/2017/ equilibrio.html

García, J. 2014. Contabilidad de costos (en línea) 4 ed. McGRAW-HILL/INTERAMERICANA (eds.), S.A. 315 p. Consultado ene. 2018. Disponible en https:// www.academia.edu/38465635/Contabilidad_de costos_4a._ed._Colin_J._2013_McGraw_Hill.pdf

Gitli, E; Arce, R. 2001. Consideraciones sobre el comercio internacional de los productos orgánicos en Centroamérica, ideas sobre Costa Rica. Centro Internacional de Política Económica para el desarrollo sostenible (en línea). Consultado 8 may. 2018. Disponible en https://www.revistavirtualpro. com/biblioteca/consideraciones-sobre-el-comerciointernacional-de-los-productos-organicos-encentroamerica-ideas-sobre-costa-rica

INEC (Instituto Nacional de Estadística y Censos). 2015. VI Censo Nacional Agropecuario 2014. 147 p. Consultado 7 oct. 2019. Disponible en https://www. inec.cr/censos/censo-agropecuario-2014

MAG (Ministerio de Agricultura y Ganadería). 2001. Reglamento de Agricultura Orgánica. Consultado 10 ago. 2018. Disponible en https://www.sfe.go.cr/ Decretos/Decreto\%20N\%C2\%B0\%2029782\%20 Reglamento\%20sobre $\% 201 \mathrm{a} \% 20$ Agricultura $\% 20$ Org\%C3\%A1nica.pdf

MAG (Ministerio de Agricultura y Ganadería). 2007. Caracterización de la agrocadena de papa, Cartago, Costa Rica (en línea). 58 p. Consultado 1 nov. 2019. Disponible en http://www.mag.go.cr/ bibliotecavirtual/E70-9453.pdf

Manual de Lumbricultura. sf. Agricultura Convencional (en línea). Consultado 20 set. 2019. Disponible en https://www.manualdelombricultura.com/glosario/ agricultura-convencional.html

Organic Latin America. 2018. Alimentos orgánicos: ¿son realmente "más caros" que los convencionales? (en línea). Consultado 20 feb. 2018. Disponible en http:// organiclatinamerica.com.ar 
Peña, E; Rodríguez, F. 2018. Finanzas: Punto de equilibrio: Análisis del punto de equilibrio de la empresa Delicias Food, SA como elemento de la gestión económica y financiera, durante el segundo semestre del año 2016. Tesis PhD. Universidad Nacional Autónoma de Nicaragua, Nicaragua. 51 p.

PIMA (Programa Integral de Mercadeo Agropecuario). 2016. Análisis del consumo de frutas, hortalizas, pescado y mariscos en los hogares costarricenses (en línea). 78 p. Consultado 16 set. 2019. Disponible en http:// www.prima.go.cr/wp-content/uploads/2017/07/ Analisis-Consumo.pdf

Sánchez, S. 2019. ¿Por qué los alimentos orgánicos son más caros que los convencionales? (en línea).
Consultado 21 ago. 2019. Disponible en https:// www.crhoy.com/economia/productos-organicospor-que-son-mas-caros/\#

SEPSA (Secretaría Ejecutiva de Planificación Sectorial Agropecuaria). 2016. Boletín Estadístico Agropecuario No 27 Serie Cronológica 2013-2016 (en línea). Consultado 18 mar. 2018. Disponible en http://www.infoagro.go.cr/BEA/BEA27/ superficieProduccion.html

SFE (Servicio Fitosanitario del Estado). 2017. Principales productos agrícolas certificados, Costa Rica 2017 (en línea). Consultado 06 feb. 2018. Disponible en https:/www.sfe.go.cr/DocsARAO/ Estadisticas_2017.pdf 